\title{
Construcción de un Inmunosensor Amperométrico utilizando Apirasa de Solanum tuberosum para la Detección de Esquistosomiasis
}

Ninoska I. Bojorge Ramírez, Mariana Fortes, Andréa Medeiros Salgado y Belkis Valdman

Universidad Federal de Rio de Janeiro, Escuela de Química, Centro de Tecnologia,

Laboratório de Biosensores, Bloco I-165, Av. Horácio Macedo, 2030, Ilha do Fundão,

21949-900 Rio de Janeiro, RJ-Brasil (e-mail: ninoska@eq.ufrj.br)

\begin{abstract}
Resumen
Este trabajo presenta el desarrollo de un inmunosensor amperométrico composito a base de una proteína de origen vegetal para la determinación de antí-anticuerpo de S. mansoni. El inmunosensor consiste en una matriz electródica rígida construida con grafito y resina epoxi en la que se inmoviliza covalentemente la Apirasa. La estrategia de inmovilización se basa en silanización de la matriz compósita con 3-aminopropilsilano (3-APTES) y su activación mediante glutaraldehído. La inmovilización fue monitoreada mediante voltaamperometría cíclica en $\mathrm{Fe}(\mathrm{CN})_{6}{ }^{4-} / \mathrm{Fe}(\mathrm{CN})_{6}{ }^{3}$, obteniéndose una respuesta cuasi-reversible del inmunosensor y muy estable en el tiempo. La inmovilización también fue caracterizada mediante ángulos de contactos y microscopía electrónica de barrido. Estas cualidades son aprovechables para la determinación clínica de esquistosomiasis dada la rapidez y sensibilidad de respuesta.
\end{abstract}

Palabras clave: proteína vegetal, inmunosensor amperométrico, inmovilización covalente, compósito

\section{Construction of an Amperometric Immunosensor using Solanum tuberosum potato Apyrase for the Detection of Schistosomiasis}

\begin{abstract}
This paper presents the development of an amperometric composites inmunosensor based on a vegetable protein for the determination of anti-Ac S. mansoni. The inmunosensor consists of a rigid matrix built with graphite and epoxy resin in which immobilizes covalently the Apyrase. The strategy of immobilization is based in silanization of the matrix composites with 3-Aminopropyltriethoxysilane (3-APTES) and its activation by glutaraldehyde. The detection was monitored by cyclic voltammetry $\mathrm{Fe}(\mathrm{CN})_{6}^{4} / \mathrm{Fe}(\mathrm{CN})_{6}{ }^{3}$, obtaining a response quasi-reversible of the immunosensor and very stable over time. The immobilization was also characterized by angles contacts and scanning electron microscopy. These qualities are useful for determination clinical of schistosomiasis given the speed of response and sensitivity.
\end{abstract}

Keywords: vegetal protein, amperometric immunosensor, covalent immobilization, composite 


\section{INTRODUCCIÓN}

La esquistosomiasis es una enfermedad conocida desde la antigüedad, cuyo parásito causador de la enfermedad fue descubierto por Bilharz (1852). Hay cinco especies en el mundo que pueden infectar al hombre, en Brasil es la Schistosoma mansoni (Maldonado et al., 1994). Actualmente, la esquistosomiasis ocupa el segundo lugar en frecuencia entre las parasitosis que afectan al hombre, y sólo es superada por la malaria. La esquistosomiasis es endémica en 74 países en vías de desarrollo y afecta aproximadamente 650 millones de habitantes (WHO, 2006); en Brasil donde la esquistosomiasis es encontrada en todas las regiones geográficas, cerca de 2.5 millones de personas son portadores de esta enfermedad, y según las estimaciones, en torno de 2 de 25 millones de personas están expuestas al riesgo de contraerla (Andrade-Filho et al., 2007). De acuerdo con el Programa Integrado de la Esquistosomiasis del Instituto de investigación Fio Cruz, (PIDE/FioCruz) la esquistosomiasis seguirá siendo un importante problema de salud global en el futuro previsible. El tratamiento con medicamentos por sí solo parece ser insuficiente para eliminar o disminuir los altos índices de positividad. El desarrollo y el refinamiento de los procedimientos convencionales de diagnósticos clínicos, tales como: Ensayo Inmunoadsorbente Ligado a Enzimas (ELISA), Inmunoensayo por Electroforesis (EI), Radio Inmuno ensayo (RIA), etc., han sido extensos (Shiguekawa et al., 2000; Oliveira et al., 2003). No obstante, la mayoría de esos métodos requieren de personal altamente calificado, de instrumentos sofisticados y mayor tiempo de análisis para su conclusión. Estos métodos han sido usados para análisis cualitativos y cuantitativos de anticuerpos de S. mansoni y sus procedimientos de diagnósticos clínicos, en general, tienen sensibilidad y especificidad de aproximadamente $70 \%$ y $90 \%$, respectivamente, lo que demanda repetición del análisis (Proietti y Antunes, 1989). Así, la búsqueda y desarrollo de nuevos métodos de diagnósticos simples y sensibles en tiempo real y de bajo costo es de gran interés.

En este sentido, los inmunosensores electroquímicos han despertados mucho interés de los investigadores, ya que satisfacen particularmente los diagnósticos clínicos y son adecuados para situaciones donde se desea la capacidad de supervisión en tiempo real (Pohanka y Skladal, 2008; Medyantseva et al., 2001). El inmunosensor se basa en la inmunoreacción del antígeno (Ag) con los anticuerpos (Ac) que son inmovilizados junto al transductor y los analitos son medidos a través de un inmunoreactivo conjugado a una enzima. Estos inmunoreactivos consisten de anticuerpos o antígenos secundarios específicos marcados o conjugados a una enzima redox. Las enzimas $\beta$ galactosidasa. Fosfatasa alcalina y Peroxidasa (HRP) son usadas extensamente como marcadoras y su sensibilidad es aumentada por una amplificación química de la señal (Presta, 2005; Hosoda et al., 1989). De modo que los inmunosensores son una herramienta con alta sensibilidad y selectividad para los inmunoensayos.

La ATP difosfohidrolasa (Apirasa, EC 3.6.1.5) fue descubierta por técnicas histoquímicas ultraestructurales en la superficie externa del tegumento de S. mansoni (Vasconcelos et al., 1993). Es obtenida del tubérculo de la patata (Solanum tuberosum) (Vasconcelos et al., 1996). Las difosfohidrolases o Apirasas del ATP son capaces de dividir el ATP o el ADP a AMP y están presentes en la superficie de diversas celdas, incluyendo las celdas de sangre y las celdas endoteliales de los vasos sanguíneos. Es una proteína de $49-\mathrm{kDa}$, posee reactividad cruzada, lo que indica que posee epítopos capaces de reaccionar en diferentes sitios del anticuerpo de S. mansoni.

Las proteínas pueden ser inmovilizadas por diversos métodos, ya sea pasivamente a través de interacciones hidrofóbicas o iónicas o por métodos de unión covalente a grupos activados en la superficie. En el primer caso, en general resulta una unión típicamente baja entre 100-200 ng $\mathrm{lgG} / \mathrm{cm}^{2}$, mientras que para superficies modificadas, resulta una alta capacidad de unión en el rango

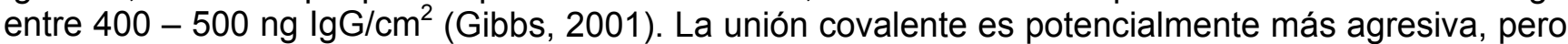
es capaz de producir una inmovilización casi irreversible de las proteínas en la superficie del sensor, que los hacen reutilizables. La inmovilización covalente puede resultar en una mejor actividad de la biomolécula, reducción de la adsorción inespecífica y una mayor estabilidad. El carácter hidrofilico/hidrofóbico del material del suporte es un factor importante, el cual determina la eficiencia de la inmovilización. En suporte a base de grafito, es necesario una modificación química de la matriz, en la cual un cierto número de anillos de benceno se rompen para producir grupos carboxilo $(-\mathrm{COOH})$ e hidroxilo $(-\mathrm{OH})$ (Willner y Katz, 2000) necesarios para la reacción de silanización. 
En este trabajo se presenta la construcción, caracterización y evaluación del empleo de la proteína Apirasa para la detección de anti-anticuerpo de S. mansoni. Mostrando el aprovechamiento biotecnológico de la Apirasa, la cual es inmovilizada covalentemente por silanización (3-APTES) tanto en una matriz compósita a base de grafito-epoxi y grafito-parafina.

\section{MATERIALES Y MÉTODOS}

\section{Equipos}

Los experimentos por voltamperometría cíclica se realizaron en un potenciostato/galvanostato Autolab PGSTAT12 (Eco Chemie, Netherlands) asociado a un software GPES (General Purpose Electrochemical System). Una celda electroquímica de $5 \mathrm{ml}$ con tres electrodos: inmunosensor como electrodo de trabajo, mini-electrodo de $\mathrm{Ag} / \mathrm{AgCl}$, como de referencia y mini-electrodo de platino como auxiliar. Las imágenes de microscopía electrónica de barrido (MEB) han sido obtenidas con un microscopio de barrido, modelo Zeiss DSM 940, del laboratorio de microscopía y microanálisis del PEMM/COPPE/UFRJ.

\section{Reactivos y materiales}

La proteína Apirasa de Solanum tuberosum (ATP-difosfatasa, E.C.3.6.1.5) usada para los inmunoensayos de detección de anti-anticuerpos de Schistosoma mansoni (Sm) y las muestras de sueros humano fueron proporcionadas por la Prof. Eveline Vasconcelos, del Departamento de Bioquímica del Instituto de Ciencias Biológicas de la Universidad Federal de Juiz de Fora. (Vasconcelos et al. 1997,1996). Como anti-anticuerpo secundario fue usado el conjugado HRP-lgG (Zymed, Cod. 62 8420). 3, 3', 5,5'-tetrametillbenzidina (TMB), 3-Aminopropiltrietoxisilane (APTES, Cas. No: 919-30-2), Glutaraldehído 25\% (GA, CAS No: 111-30-8) y tampón Glicina/HCl (Cat. No. 82668) fueron subministrados por Sigma-Aldrich. Grafito en polvo (Cas. No: 7782-42-5, Fluka Chemie AG, USA); resina epoxi y activador de epoxi Epo-Tek H77, (Epoxi Brasil) Se usaron etanol absoluto y 0,2 M etanolamina (Cas No: 141-43-5). Las soluciones acuosas se prepararon con agua Milli-Q. La solución tampón bloqueador consistió de $2 \%$ de caseína (Cas No: 9000-71-9) y 0,05\% de Tween 20 (Cas No: 9005-64-5) en tampón PBS (pH 7.2). La solución de tampón de lavado consistió de $0,05 \%$ de Tween 20 en PBS (pH 7.2). La solución de tampón de carbonato (pH 9.2) fue usada para diluir la proteína Apirasa. Todos los otros productos fueron de grado analítico o similar.

\section{Construcción del Inmunosensor}

La preparación del compósito grafito - epoxi y la inmovilización covalente de la Apirasa fue similar al descrito por Bojorge et al. 2007. Brevemente consistió en el pre-tratamiento de la matriz de grafito con $\mathrm{H}_{2} \mathrm{O}_{2}$ para incorporar grupos hidroxilos El grafito en polvo pre-tratados con peróxido y la resina epoxi se mezclaron en la proporción $1: 4(\mathrm{~m} / \mathrm{m})$. La pasta resultante se colocó en un extremo de un tubo cilíndrico de PVC de 1,7 mm de diámetro interno, de $6 \mathrm{~mm}$ de diámetro externo y de $50 \mathrm{~mm}$ de longitud al que se le acopló de un lado del tubo un alambre de cobre, previamente limpiado con una solución de $\mathrm{HNO}_{3}$ al $5 \%$ a fin de eliminar la capa de oxido que pudiese tener (la cual puede interferir en su conductividad). En el otro extremo quedó una cavidad de aproximadamente $3 \mathrm{~mm}$ a una profundidad de $3 \mathrm{~mm}$ en y $1,5 \mathrm{~mm}$ de diámetro interno) y del otro lado hace contacto eléctrico. La inmovilización de proteínas Apirasa se basó en la sinalización con 3-APTES y la activación con glutaraldehido. Cuando no era utilizado, el inmunosensor fue almacenado en seco a $4{ }^{\circ} \mathrm{C}$.

\section{Procedimiento del Inmunoensayo}

Se realizaron inmunoensayos ELISA indirecto a fin de determinar a intensidad y/o concentración de anti-anricuerpos (SmAb) en muestras. La figura 1 muestra un diagrama esquemático del procedimiento de análisis. El inmunosensor fue incubado en $200 \mu \mathrm{L}$ de tampón PBS con el anticuerpo primario seguido de la adición del anticuerpo secundario o marcador (HRP-lgG) (dilución 1:3000) a temperatura ambiente. Posteriormente, el inmunosensor es enjuagado completamente con tampón de lavado, para remover cualquier marcador no ligado. El electrodo es colocado en la celda electroquímica de $4 \mathrm{ml}$ con $0.1 \mathrm{~mol} \mathrm{~L}^{-1}$ de tampón citrato ( $\mathrm{pH}$ 5.5). Después de la adición de $100 \mu \mathrm{L}$ 
de una mezcla de substrato TMB y $\mathrm{H}_{2} \mathrm{O}_{2}$ (concentración final de $5 \times 10^{-4} \mathrm{~mol} \mathrm{~L}^{-1}$ y $1 \times 10^{-3} \mathrm{~mol} \mathrm{~L}^{-1}$, respectivamente), la respuesta amperométrica es medida. Esta respuesta amperométrica es registrada $a+100 \mathrm{mV}$ versus $\mathrm{Ag} / \mathrm{AgCl}$. Se considera que la señal generada es inversamente proporcional a la cantidad de anticuerpos presentes en la muestra.

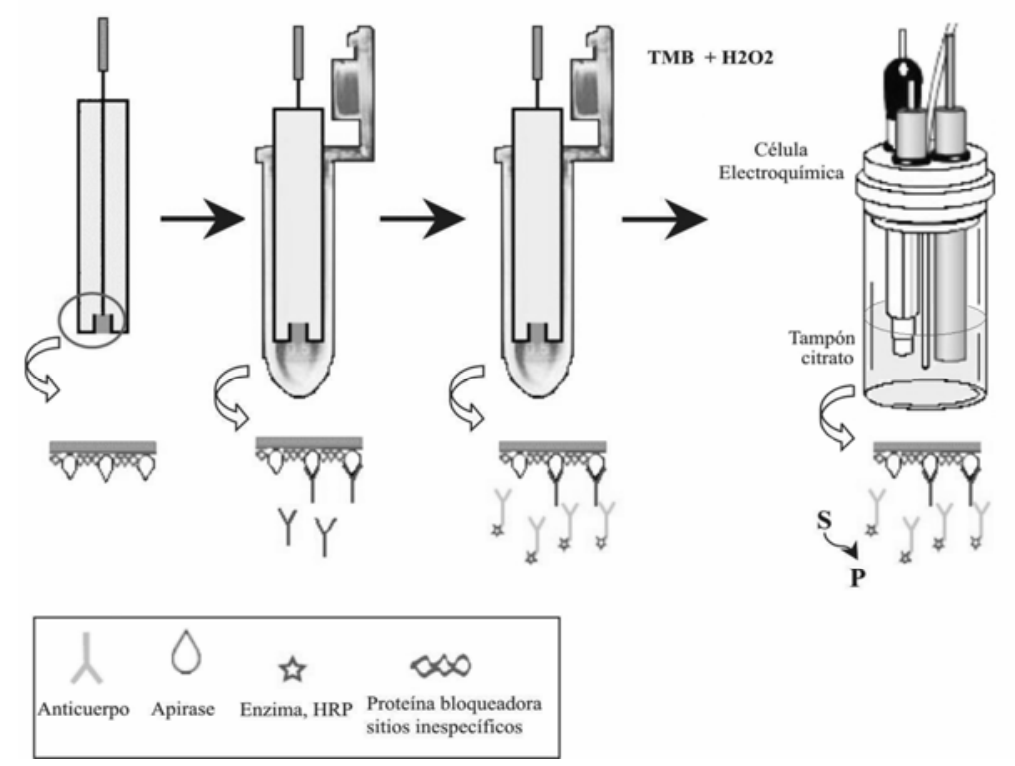

Fig.1: Diagrama del procedimiento del inmunoensayo ELISA Indirecto.

\section{RESULTADOS Y DISCUSIÓN}

\section{Comparación de compósitos}

Se realizó la construcción y evaluación de dos tipos de compósitos: grafito-parafina y grafito- epoxi. La caracterización de estos compósitos/transductores se realizó tanto electroquímicamente como microscópicamente. Un compósito es la combinación de dos o más fases de diferente naturaleza, el cual tiene la función de soporte de los inmuno-reactivos y de transductor. En el presente trabajo, se seleccionó como transductores electroquímicos compósitos rígidos basados en polímeros al que se le agregó, como material conductor, grafito en polvo. Este tipo de material ha sido utilizado diversamente en la construcción de biosensores amperométricos por varios investigadores (Kameswara et al., 2005; Tong-Sheng y Liu, 2004; Zhou et al. 2003; Ivnitski y Rishpon, 1996). En la literatura se han presentados diversos sensores amperométricos cuyos electrodos se regeneran con un simple pulido de su superficie (Zacco et al. 2004). Entre las matrices utilizadas para la inmovilización del elemento de reconocimiento se encuentran las matrices electródicas compósitas de grafito-parafina y de grafito-resina epoxi (GEC). La rigidez del compósito otorga ventajas físicomecánicas y aumenta la robustez del dispositivo (Zacco et al. 2004; Santandreu et al. 1997; Alegret, 1996,) ya que combinan rigidez física, hinchamiento insignificante en solución acuosa, inercia química y estabilidad térmica. En cuanto a sus propiedades electroquímicas, el carácter dual de la superficie de la matriz compósita, compuesta de partículas de grafito en un medio polimérico circundante, promueve una mayor transferencia de masa en comparación con lo que acontece con superficies continuas de materiales conductores puros, tales como grafito, oro, etc. Tienen alta sensibilidad y tiempo de respuesta rápido, así como también están libres del problema de generar efecto perjudicial sobre la actividad enzimática. Por otro lado, está la ventaja de la facilidad de preparación y de modificación en volumen y, por tanto, del control de los componentes biológicos que se reponen en la superficie.

La preparación del compósito de grafito-parafina es bastante sencilla y rápida. Esta pasta fue introducida en la cavidad del sensor con ayuda de una espátula y de esa manera queda listo para su uso. Lo critico en esta fase, es la correcta homogenización de la formulación del compósito a fin de asegurar una distribución uniforme, y obtener superficies reproductivas después de cada pulido. No obstante, el compósito de resina epoxi-grafito requiere de un mayor tiempo para el proceso de 
curado (96 horas a temperatura ambiente). Pero, tiene la ventaja de ser un compósito más rígido y no sufre desorción, estimulada por condiciones térmicas y de flujo.

En la figura 2 se muestran las imágenes obtenidas por microscopía electrónica de barrido (MEB) para ambos compósitos. Como puede observarse en figura 2A la superficie del compósito grafitoparafina $(P G)$ es mas heterogénea y rugosa que la del GEC (Figura 2B). Las zonas claras se atribuyen al polímero y las oscuras al material conductor; el grafito. La figura 2C muestra la respuesta voltamperométrica del medio electrolítico sin substrato en tampón citrato para ambos compósitos en el intervalo de potenciales de $-200 \mathrm{mV}$ a $280 \mathrm{mV}$. El compósito PG de grafito-parafina exhibe valores mayores de corriente de fondo que de GEC. La corriente de fondo se puede atribuir principalmente al área superficial y a la gran porosidad del compósito grafito-parafina.
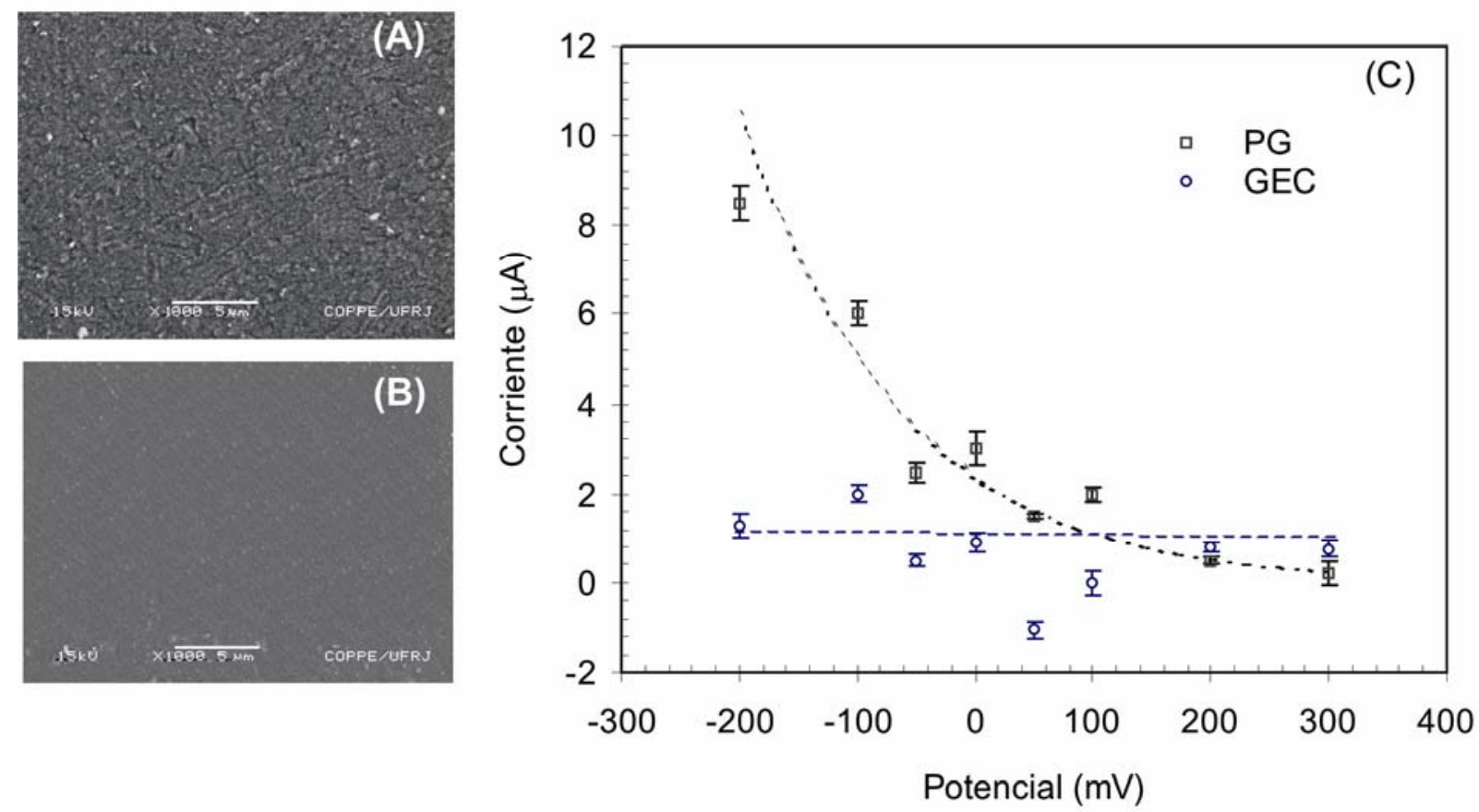

Fig. 2: Comparación de imágenes de las superficies de compósitos, obtenidas por MEB, 1000X: (A) compósito de grafito-parafina (PG), (B) compósito de grafito-epoxi (GEC); Perfiles de corriente de fundido a diferentes potenciales aplicados $(\mathrm{C})$ en tampón citrato, $0.1 \mathrm{~mol} . \mathrm{I}^{-1}$, $\mathrm{pH} 5.5$.

\section{Desempeño electroquímico}

La preparación del inmunosensor de SmAg basado en el compósito GEC es también relativamente simple y sus características voltamperométricas son satisfactorias. La figura 3 demuestra el funcionamiento de los voltamogramas de la solución del ferrocianuro del potasio obtenida con el inmunosensor grafito-de epoxi. La diferencia de potenciales químico $(\Delta \mathrm{Ep})$ correspondiente es -350 $\mathrm{mV}$ a $100 \mathrm{mV} \mathrm{s}{ }^{-1} ; \mathrm{Ip} / \mathrm{V}^{1 / 2}$ permanece constante cuando la velocidad de barrido varia (véase el recuadro de la figura figura 3). Para los diversos voltamogramas observados el sistema es cuasireversible. Los valores del $\Delta \mathrm{Ep}$ medidos para compósitos-GEC son reproducidos con una desviación de estándar menor al $10 \%$.

\section{Optimización de las condiciones del análisis}

El objetivo de estos tests fue optimizar los parámetros experimentales del procedimiento del inmunoanálisis, cuando la concentración de Apirasa inmovilizada en la superficie del transductor fue fijada en $5 \mu \mathrm{g} / \mathrm{ml}$, nivel estandarizado de concentración empleado en los ensayos ELISA convencionales de esquistosomiasis. Uno de los parámetros experimentales que afecta el inmunoensayo es la temperatura de incubación de Ag-Ac. Diversas temperatura de incubación han sido reportadas en la literatura, variando de 25 a $37{ }^{\circ} \mathrm{C}$ (Sun et al. 2006; Santandreu et al.,1997). Como es bien sabido, la temperatura óptima de la inmunoreacción es $37^{\circ} \mathrm{C}$. Las proteínas exhiben 
una mejor actividad para el rango de temperatura entre 20 a $25^{\circ} \mathrm{C}$. A temperaturas superiores puede ocurrir un decaimiento de su actividad y especificidad. Este efecto de la temperatura fue examinado monitoreando la respuesta amperométrica del inmunosensor entre 5 a $40{ }^{\circ} \mathrm{C}$. En la figura $4 \mathrm{~A}$ se observa que la señal aumenta a medida que aumenta la temperatura, presentando un máximo en 28 ${ }^{\circ} \mathrm{C}$, y luego disminuye para temperaturas más altas. La pérdida de señal a temperaturas más altas se atribuye al efecto conjunto de la temperatura y del $\mathrm{pH}$ de la solución de la incubación, que disminuye 0.3 unidades de $\mathrm{pH}$ con un aumento de la temperatura de la incubación que se extiende a partir el 28 ${ }^{\circ} \mathrm{C}$ a $40{ }^{\circ} \mathrm{C}$ (inserción de la figura $4 \mathrm{~A}$ ). Por otro lado, la reacción de la silanización usando APTES en el compósito GEC es sensible al calor. Una temperatura más alta afectaría su estabilidad física, y por tanto, a un aumento de la corriente de fondo y deterioro de la sensibilidad del sensor. Para simplificar el análisis se seleccionó la temperatura ambiente (controlada en $25^{\circ} \mathrm{C}$ ) como temperatura de incubación, la cual fue utilizada en todos los experimentos.

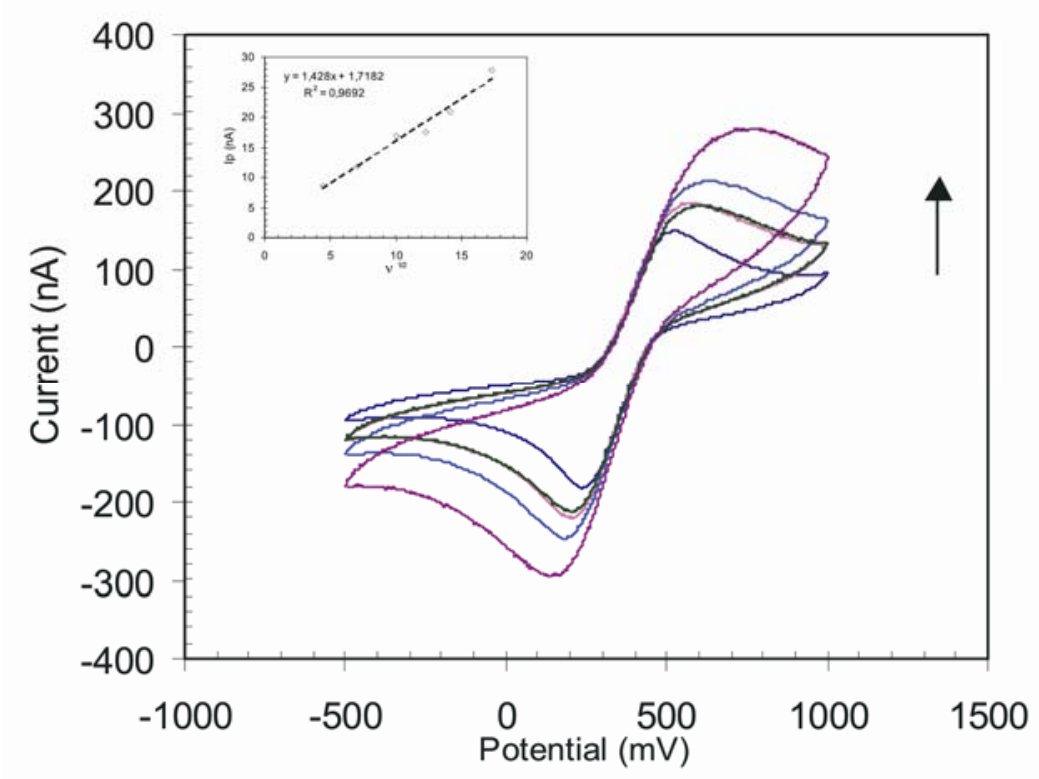

Fig. 3: Voltamograma cíclico del inmunosensor de grafito-epoxi $(60: 40 \mathrm{~m} / \mathrm{m})$ en solución de $1 \mathrm{mM} \mathrm{K}_{3} \mathrm{Fe}(\mathrm{CN})_{6}$ en $0.1 \mathrm{M} \mathrm{KCl}$. Velocidades de barrido de $50 \mathrm{mV} \mathrm{s}^{-1}, 100 \mathrm{mV} \mathrm{s}^{-1}, 150 \mathrm{mV} \mathrm{s}^{-1}$, $200 \mathrm{mV} \mathrm{s}^{-1}$ y $300 \mathrm{mV} \mathrm{s}^{-1}$.

La respuesta amperométrica del inmunosensor depende también de la cantidad de anti-anticuerpo conjugado (HRP-lgG) empleado en el ensayo. Para determinar este efecto fueron medidas las respuestas amperométricas del inmunosensor incubado en varias soluciones de tampón de incubación de mayor a menor dilución de HRP-lgG, En la figura 4B se observa que la intensidad de corriente aumentó linealmente hasta $0.375 \mathrm{mg} / \mathrm{mL}$ de HRP-lgG en la solución y después alcanzó un nivel de saturación. Para concentración más baja de HRP-lgG se obtiene una disminución de la detección de SjAb en las soluciones debido a que los epítopos de la superficie de la proteína Apirasa inmovilizada en el inmunosensor son limitados. Por lo tanto, $100 \mu \mathrm{L}$ de la solución final de HRP-lgG (dilución $1: 3000$ de $0.75 \mathrm{mg} / \mathrm{mL}$ de HRP-lgG) fue utilizado rutinariamente para la incubación del conjugado en estos análisis.

En la figura 4C se muestra el efecto del pH de la solución del análisis en la respuesta amperométrica del inmunosensor grafito-epoxi a través de las medidas de las intensidades amperométricas del inmunosensor, previamente incubado con $5 \mathrm{\mu g} \mathrm{ml}^{-1}$ de Apirasa y de $2.5 \mathrm{ng} \mathrm{ml}^{-1} \mathrm{HRP}$-lgG por 45 minutos en tampón citrato $0.1 \mathrm{~mol} \mathrm{I}^{-1}$ en diversos $\mathrm{pH}$. El rango óptimo de $\mathrm{pH}$ del tampón fue entre 4.5 a 6.5. En los experimentos fue utilizado tampón citrato $\mathrm{pH} 5.5$ para los ensayos con el inmunosensor. El último parámetro estudiado fue el tiempo de incubación del inmunosensor. En la figura 4D se observa que la señal amperométrica aumenta con el tiempo de incubación para el intervalo de 10 a 30 minutos, y luego esta señal permanece relativamente constante, lo que se atribuye a una consecuencia de los efectos totales de la interacción, cuando la concentración de SjAb libres es 
menor. Para tiempos de incubación de 50 minutos se observó que la señal tiende ser estable, y de esta manera se fijó 50 minutos como tiempo óptimo de incubación para los experimentos.
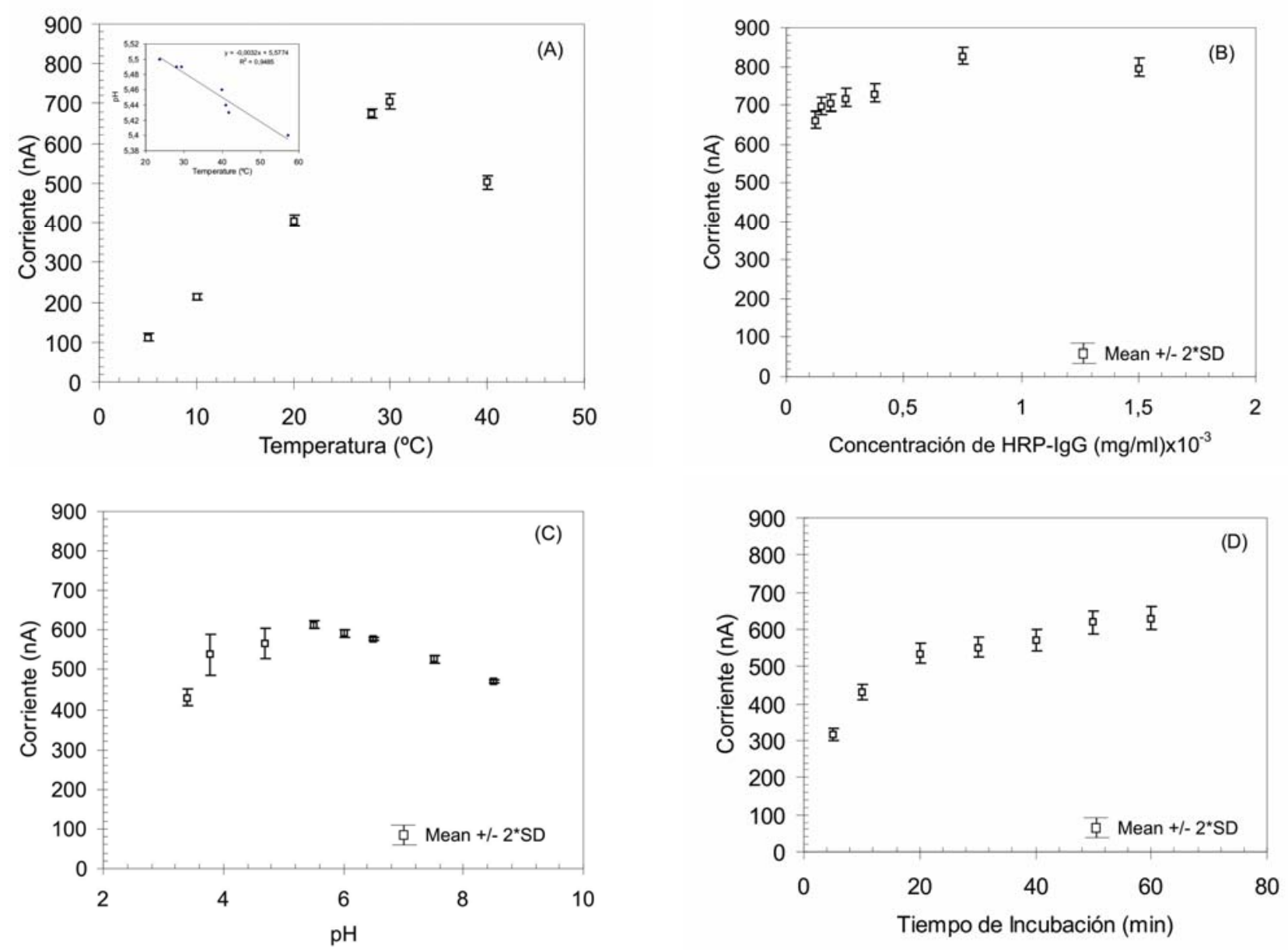

Fig. 4: Efecto de los parámetros operacionales del inmunosensor: (A) Efecto de la temperatura de inoculación; (B) Efecto de la concentración de HRP-IgG inoculado a $25^{\circ} \mathrm{C}$ durante $30 \mathrm{~min}$; (C) Variación del $\mathrm{pH}$ del tampón citrato $0.1 \mathrm{~mol} \cdot \mathrm{L}^{-1}$ del inmunosensor; (D) Variación del tiempo de inoculación del inmunosensor conteniendo $5 \mu \mathrm{g} / \mathrm{ml}$ de Apirasa $(n=3)$.

\section{Funcionamiento del inmunosensor}

Una vez optimizados los parámetros experimentales, se utilizó el inmunosensor para determinar la reactividad tanto para sueros de pacientes positivos como negativos, procedentes de una sueroteca previamente confirmados por ensayos convencionales (ELISA e inmuno-fluorescencia indirecta), y sin identificación de las correspondientes muestras de los pacientes. La reactividad se basa en la determinación estadística de la línea de corte, como dos veces el desviación estándar de la media de los controles negativos.

Se realizaron inmunoanálisis por voltamperometría cíclica con muestras de sueros estándar en triplicado para cada dilución. Las medias muestrales de las respuestas amperométricas para los controles negativos en la dilución 1:100, 1:400, 1:1600 y 1:3200 fueron de $522 \pm 53 \mathrm{nA}, 373 \pm 55 \mathrm{nA}$, $327 \pm 60 \mathrm{nA}, 241 \pm 50 \mathrm{nA}$ respectivamente. Para las diluciones entre 1:400 y 1:1600 las variaciones de la intensidad amperométrica no fueron significativas, por lo que el control es más sensible para la dilución 1:100. Así, para la media de las intensidades obtenidas en la dilución 1:100, fue añadido dos veces la desviación estándar, lo cual establece el punto inicial de la reactividad en aproximadamente $628 \mathrm{nA}$. De modo que una muestra se considera no reactiva cuando la intensidad de corriente obtenida es igual o inferior a 628nA y reactiva cuando los valores son superiores a este valor. 
Las figuras $5 \mathrm{~A}$ y $5 \mathrm{~B}$ muestran las variaciones de los valores promedios de las intensidades voltamperométricas para muestras de sueros de pacientes negativos (AN) y muestras de sueros positivos (AP), respectivamente. Como puede observarse todos los sueros de pacientes infectados con esquistosomiasis presentaron valores de intensidad de corriente superiores que los respectivos promedios de las reactividades para cada dilución. La menor intensidad de corriente promedia obtenida para los sueros de control negativo fue de 464.1nA correspondiente a la dilución 1:100. A partir de estos valores se obtuvo la curva de calibración para diferentes diluciones realizadas con los sueros de control positivo, la cual se muestra a la derecha de la Figura 5 . El punto de corte fue determinada para la dilución de 1:2400, lo que demuestra la alta sensibilidad de la metodología propuesta. La duración del análisis de $\mathrm{Ag}-\mathrm{Ab}$ *- Ab utilizando el método alternativo de inmunosensor electroquímico fue de 40 a 50 minutos.
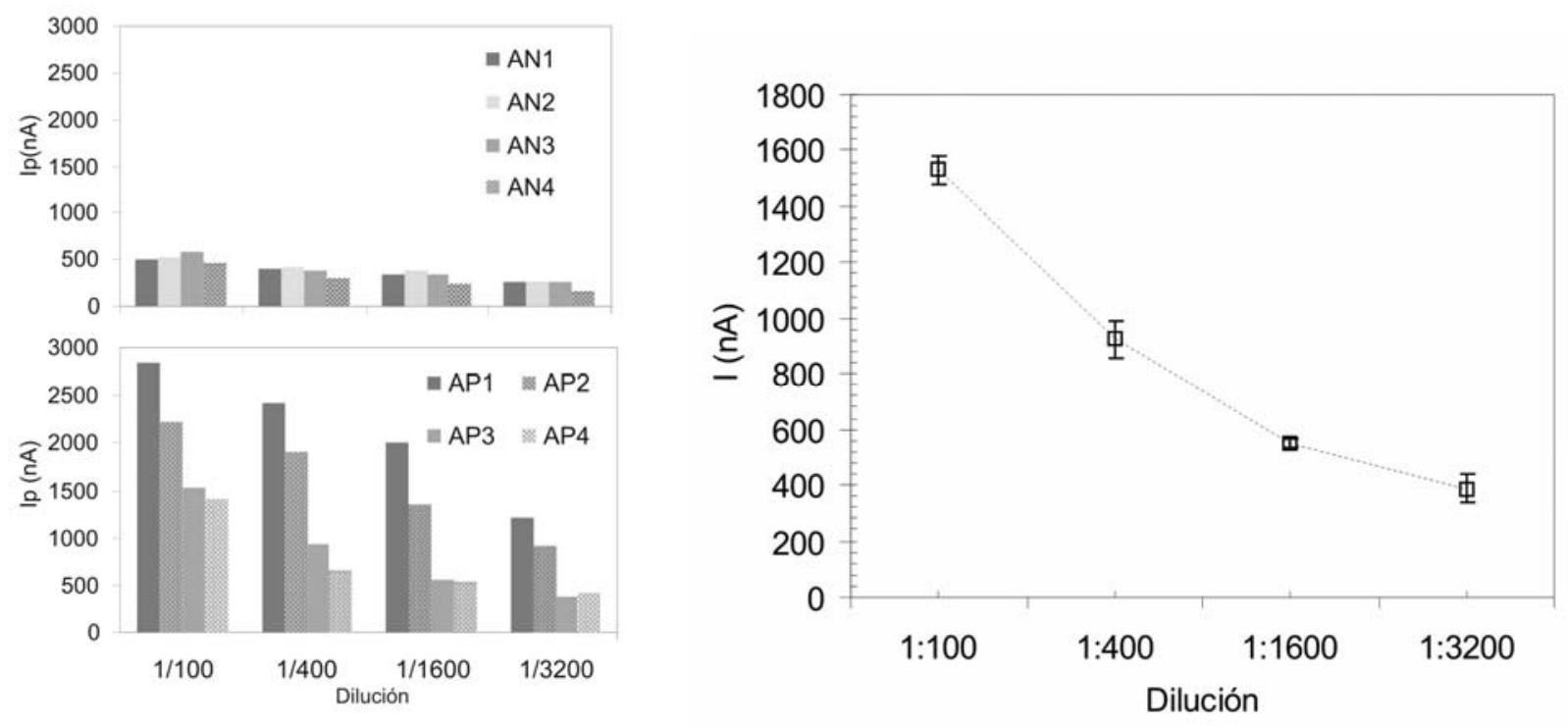

Fig.5: Respuesta del inmunosensor en muestras estándar de sueros de pacientes y la curva de calibración de 4 puntos se obtuvo por diluciones seriadas $(n=3)$. (AN: Muestra estándar de control negativo, AP: muestra estándar de control positivo) y curva de calibración para diluciones de muestras de SmAb en $0.1 \mathrm{~mol} \mathrm{~L}^{-1}$ de tampón citrato $(\mathrm{pH} 5.5)$.

\section{CONCLUSIONES}

El uso del compósito GEC para la inmovilización de la proteína Apirasa fue probado con éxito como dispositivo de detección para detectar la concentración de los anticuerpos de S. mansoni. El compósito GEC es menos poroso al ser comparado con la pasta de grafito-parafina. El compósito GEC es altamente moldeable antes de curarse, lo que permite flexibilidad para la construcción del inmunosensor; es rígido y estable desde el punto de vista mecánico a temperatura moderada. La superficie del compósito GEC se puede renovar mediante tampón acido o con simple pulido de la superficie transductora. El rango del potencial de trabajo y de baja corriente de fondo hace factible el uso del inmunosensor amperométrico para el análisis clínico en muestras de sueros para diagnosis de la esquistosomiasis.

\section{AGRADECIMIENTOS}

A la profesora Eveline G. Vasconcelos del ICB/UFJF y a los apoyos financieros del Conselho Nacional de Desenvolvimento Científico e Tecnológico (CNPq) (Proceso No:150427/2004-2), Proyecto Universal (Proc: 473233/2007-0) y a la FAPERJ (Proceso No. E-26/150.997/2006).

\section{REFERENCIAS}

Alegret S.; Rigid carbon-polymer biocomposites for electrochemical sensing. A review, Analyst: 121, 
$1751-1758$ (1996).

Andrade-Filho S. A. y otros siete autores; Pseudotumoral Form of Neuroschistosomiasis: Report of Three Cases, The Brazilian Journal Of Infectious Diseases: 11 (4), 435-438 (2007).

Bilharz T.M.; Fernere Beobachtungen uber das die Pfortader des Menschen bewohnende Distonum haematobium und sein zu gewissen: Wschift Zol Leipzig: 4, 72-76 (1852).

Bojorge Ramírez N I., A.M Salgado, B. Valdman; Amperometric Immunosensor for Detecting Schistosoma mansoni Antibody, ASSAY and Drug Development Technologies: 5(5), 673-682 (2007).

Gibbs, J,.; Immobilization Principle - Selecting the Surface; Elisa Technical Bulletin - No. 1, Corning Life Sciences, Kennebunk, Maine (2001), Disponible en Internet: http://www.corning.com/ lifesciences/technical_information/techdocs/elisa1.asp [ Accesado en 10 de Junio de 2007].

Hosoda H., R. Tsukamoto y T. Nambara; Sensitivity of steroid enzyme immunoassays. Comparison of four label enzymes in an assay system using a monoclonal anti-steroid antibody. Chemical \& pharmaceutical bulletin: 37(7),1834-7 (1989).

Ivnitski D. y J. Rishpon; A one-step, separation-free amperometric enzyme immunosensor. Biosensor and Bioelectronic: 11(4), 409-417 (1996).

Kameswara R.V., G.P. Rai, G.S.Agarwal y S.Suresh, Amperometric immunosensor for detection of antibodies of Salmonella typhi in patient serum, Analytica Chimica Acta: 531, Issue 2(28), 173-177 (2005).

Maldonado Jr. A. y otros cinco autores; Evaluation of the resistance to Schistosoma mansoni infection in Nectomys squamipes (Rodentia: Cricetidae), a natural host of infection in Brazil. Revista do Instituto de Medicina Tropical de São Paulo: 36(3), ISSN 0036-4665 (1994).

Medyantseva E.P., E.V. Khaldeeva y G.K. Budnikov; Immunosensors in Biology and Medicine: Analytical Capabilities, Problems, and Prospects, Journal of Analytical Chemistry: 56(10), 886-900 Translated from Zhurnal Analiticheskoi Khimii, 1015-1031 (2001)

Oliveira E.J. y otros siete autores; ELISA-IgM para diagnóstico da esquistossomose mansoni em área de baixa endemicidade. Cad. Saúde Pública, Rio de Janeiro: 19(1), 255-261 (2003).

Pohanka M. y P. Skladal; Electrochemical biosensors - principles and applications, Review, J. Appl. Biomed.: 6, 57-64 (2008), ISSN 1214-0287.

Presta L.; Selection, design, and engineering of therapeutic antibodies. J. Allergy Clin Immunol.: 116(4), 731-736 ( 2005).

Proietti F.A y C. M. Antunes; Sensitivity, Specificity and Positive Predictive Value of Selected Clinical Sings and Symptoms Associated with Schistosomiasis Mansoni, Int. J. Epidemiol.: 18, 680-683 (1989).

Santandreu M., F. Céspedes, S. Alegret y E. Martínez-Fàbregas; Amperometric immunosensor based on rigid conducting immunocomposites. Anal. Chem.: 69, 2080-2085 (1997).

Shiguekawa M.K.Y, J.R. Mine, L.P. Moura y J.M. Costa-Cruz; ELISA and Western Blotting tests in the detection of IgG antibodies to Taenia solium metacestodes in serum samples in human neurocysticercosis, Tropical Medicine and International Healt: 5 (6), 443-449 (2000).

Sun D., A. Mcnicol, A.A. James y Z. Peng; Expression of functional recombinant mosquito salivary apyrase: A potential therapeutic platelet aggregation inhibitor, Platelets: 17(3), 178-184 (2006).

Tong-Sheng Zhong y Guodong Liu; Silica sol-gel amperometric immunosensor for Schistosoma 
japonicum antibody assay. Analytical Sciences: (20), 537-541(2004).

Vasconcelos, E.G. y otros siete autores; Partial purification and imunohistochemical localization of ATP diphosphohydrolase from S. mansoni. Imunological cross reactivities with potato apyrase and Toxoplasma gondii nucleoside triphosphate hydrolase. J. Biol. Chem.: 271, 22139-22145 (1996).

Vasconcelos, E.G. y otros cuatro autores; Characterization and localization of an ATP diphosphohydrolase on the external surface of tegument of Schistosoma mansoni. Mol. Biochem. Parasitol.: 58, 205-214 (1993).

Vasconcelos, E.G. y otros cuatro autores; The ATP-diphosphohydrolase of S. mansoni: Ectolocalization and possible roles in host-parasite interactions. In Ecto-ATPases, (L. Plesner, T.L. Kirley, and A.F. Knowles, eds), Plenum Publishing Corp., 221-226 (1997).

Willner I. y E. Katz; Integration of Layered Redox-Proteins and Conductive Supports for Bioelectronic Applications. Angew. Chem., Int. Ed.: 39, 1180-1218 (2000). Cover picture of the issue, p. 1143

WHO (World Health Organization); Schistosomiasis In-Progress 1995-1996: Thirteenth Programme Report of the UNDP/World Bank/WHO Special Programme for Research and Training Diseases. Geneva: http://www.who.int/tdr/svc/diseases/schistosomiasis.Acceso: 30 de agosto de 2006.

Zacco E. y otros cuatro autores; Renewable protein a modified graphite-epoxy composite for electrochemical immunosensing. Journal of Immunological Methods: 286(1-2), 35-46 (2004).

Zhou Y-M, Shen-Qin Hu, Gou-Li Shen, Ru-Qin Yu; An amperometric immunosensor based on an electrochemically pretreated carbon/paraffina electrode for complement III (C3) assay. Biosensors and Bioelectronics: 18, 473-481 (2003). 